\title{
O projeto Marcados, de Claudia Andujar: uma discussão sobre práticas e gêneros fotográficos
}

\section{Daniela Nery Bracchi}

Doutora; Universidade Federal de Pernambuco, Caruaru, PE, Brasil bracchi@gmail.com

\section{Paula Soares}

Doutoranda; Universidade Federal Fluminense, Niterói, RJ, Brasil splsoares@gmail.com

\section{Resumo}

Este trabalho parte da análise plástica de retratos de indígenas realizados pela fotógrafa Claudia Andujar, de forma a explorar o sentido dessas imagens ao longo do tempo em seu percurso em diferentes suportes e contextos de exposição. O objetivo do trabalho apresenta-se como a análise da variedade de modos pelos quais esses retratos circulam e firmam-se como pertencentes a práticas interpretativas distintas. Para tal investigação, a metodologia utilizada é a análise dos níveis de significação propostos por Fontanille em sua pesquisa sobre as práticas semióticas e, mais diretamente, os desdobramentos realizados por Dondero \& Basso Fossali ao proporem uma Semiótica da Fotografia. A análise atinge, principalmente, a conclusão sobre importantes mudanças no modo de interpretação dessas imagens no fotolivro e nas exposições, uma vez que se apresenta constantemente a tensão entre a apreensão dessas fotos enquanto documento e sua inscrição no âmbito artístico.

\section{Palavras-chave}

Fotografia. Retrato. Claudia Andujar.

\section{Breve introdução sobre os níveis de pertinência na análise de fotografias}

A problemática da fotografia costuma ser analisada, principalmente, pela sociologia, pela filosofia, pela antropologia e por abordagens que tendem a estudar o tema a partir de 
uma reflexão geral sobre o meio fotográfico ou de uma história das técnicas, deixando de lado duas questões fundamentais: a análise de fotografias e a problematização de seus usos e de seu estatuto (DONDERO; BASSO FOSSALI, 2011).

No entanto, a fotografia como objeto cultural tem sido campo de férteis estudos que reconhecem seu significado a partir dos modos pelos quais se dá a ver e circula em sociedade. A contribuição da Semiótica de linha francesa, que vai ao encontro desse tipo de estudo, é a abordagem das práticas semióticas, que nasceu de uma necessidade de reorganizar os limites entre a imanência postulada pela vertente canônica da teoria e a fixação das suas fronteiras, apontando para o fato de que o texto escrito ou verbal em si não é apenas o objeto de estudo dos semioticistas, que passam a trabalhar também com objetos materiais, práticas ou formas de vida que estruturam uma determinada cultura (FONTANILLE, 2008).

Nessa empreitada, são criados níveis de pertinência semiótica em seis planos de imanência - (1) signos e figuras, (2) textos-enunciados, (3) objetos e suportes, (4) cenas e práticas, (5) situações e estratégias, (6) formas de vida - e, a partir deles, podemos melhor analisar a fotografia, levando em consideração não somente o texto fotográfico em si, mas os diversos aspectos que o acompanham. A maneira como a foto circula em diferentes situações semióticas e quais significados vão sendo encadeados a partir de seus modos de exibição são especialmente relevantes nos estudos sobre fotografia. Isso significa considerar as imagens a partir dos modos pelos quais elas se dão a ver em instituições como museus e galerias, ou ainda o modo como são exibidas em livros, catálogos e revistas de nicho, analisando, inclusive, elementos como moldura, suporte, posicionamento das imagens, relação com outras imagens, etc.

De forma resumida, trata-se de integrar o contexto ao objeto de análise, tornando-o um elemento de pertinência para o entendimento dos sentidos construídos pela imagem e sua exposição (FONTANILLE, 2008). Considera-se, portanto, que a textualidade fotográfica é tomada como um enunciado resultante de diversas práticas de enunciação dentro de determinada cultura, de modo que se tornam relevantes não só as características do plano de expressão semiótico (textos-enunciados), como as inscrições de sua produção e circulação (objeto), até as práticas (tanto produtivas quanto interpretativas, mais ou menos sedimentadas) de que o texto fotográfico participa. São as cristalizações das práticas referentes à produção e interpretação das fotografias que permitem construir um mínimo 
de território específico desse meio no espaço dos interdomínios sociais, conforme salienta Dondero e Basso Fossali (2011).

0 que está em jogo aqui é a compreensão de que a obra fotográfica pode ser considerada a partir de diferentes níveis de existência semiótica. 0 nível de análise do texto visual é diferente daquele da fotografia enquanto parte de práticas e estatutos específicos (tais como o artístico, documental, por exemplo), e mesmo de considerações mais amplas sobre seu caráter cultural e as indicações sobre os modos de vida assumidos socialmente que as imagens deixam entrever.

É possível compreender melhor a existência de níveis de análise semiótica a partir das conceituações de Fontanille, retomadas por Dondero e Basso Fossali em 2011. Elas ajudam a situar melhor as possibilidades de entendimento da fotografia e compreender a construção de sentido da imagem fotográfica dentro de cada um desses patamares de análise, de modo que cada um desses níveis seja constituído de um plano de expressão e de conteúdo. É possível resumir aqui a abordagem de cada um desses níveis de análise tendo como horizonte o estudo das fotografias. 0 primeiro nível é aquele dos signos, mas, sendo a semiótica da Escola de Paris uma investigação já sobre os textos e, portanto, mais abrangente do que o nível dos signos, trata-se as questões sobre iconicidade em conjunto com aquelas sobre a produção de efeitos veridictórios.

Já ao nível de análise dos textos-enunciados, os desenvolvimentos atuais da semiótica da fotografia colocam atenção sobre a enunciação nos textos visuais, considerando as marcas de subjetividade no modo de enunciar, entendidas sob o conceito de enunciação enunciada. 0 enunciador pode deixar claro seu papel de construção do enunciado por meio da materialização de sua figura no enunciado, pelo jogo entre actantes e atores ou ainda por determinadas interferências plásticas. Trata-se, portanto, de privilegiar uma dimensão plástica da fotografia, à qual está atrelada uma intencionalidade do enunciador e a experiência da compreensão do sentido da imagem.

Do signo e do texto enunciado, passa-se à consideração da fotografia como objeto, compreendida em sua materialidade. Isso significa colocar em relevo a experiência da corporeidade, resgatando as marcas de uso, do tempo de produção e do papel da fotografia como objeto em meio a outros (sua integração no álbum fotográfico, sua exposição museográfica, etc.).

Uma determinada situação de exposição de uma fotografia faz da imagem uma participante de uma cena prática. Nesse sentido, interessa investigar as ações em curso que 
constroem a significação de uma situação semiótica e sua transformação. Presta-se especial atenção ao encadeamento de ações, cada uma delas tendo seu plano de expressão concretizado pelas propriedades sensíveis e plásticas (nível do objeto) dos corpos colocados em relação. Quando pensamos o ambiente das imagens fotográficas e as práticas com que podemos nos deparar no presente estudo, estamos especialmente alertas às ações que as situações de exposição das fotografias levam o enunciatário a percorrer. Falamos aqui do papel actancial das fotografias, a ação que elas conclamam o enunciatário a fazer, pois tais ações são formadoras de um contexto interpretativo maior, no qual se dará a construção da significação. O primeiro objeto e contexto de exposição a ser considerado, o fotolivro, inscreve ações como o folhear de páginas (com suas idas e vindas), além da sustentação do objeto livro sobre o corpo do leitor e a escala de tal objeto em relação àquela definida pelo corpo do enunciatário. Todas essas ações pertencem a práticas já consolidadas, abarcam expectativas criadas sobre como deve se desenvolver o envolvimento com um fotolivro e são advindas diretamente de uma história de fruição dos livros de artista.

Conforme nos alerta Fontanille (2008, p. 5), entre ações sedimentadas e a emergência de outras inesperadas é que se formam escolhas sintagmáticas das práticas que as situam numa escala entre programação e ajustamentos constantes da interação entre enunciatário e o texto fotográfico exposto em determinado contexto. Entendemos, ainda, que cada leitor atualiza as ações que compõem a relação com o fotolivro tendo como pano de fundo a história e as expectativas sobre quais ações são essas e como elas devem se encadear ao longo do tempo de contato com a obra. Já quando falamos das fotografias expostas em um museu, um outro conjunto de ações é expresso no tempo, guardando consigo outras expectativas quanto aos tipos de movimento e seu papel na construção de sentido das imagens.

Avançando nos níveis das práticas, percebemos que a subversão do papel actancial da fotografia é um dos indicativos de que existe um nível maior de análise, o das estratégias, que se preocupa com as estabilizações e rupturas das práticas a partir das normas produtivas e interpretativas constituídas ao longo da história de exposição de certo tipo de imagem. É importante salientar que o gênero das imagens pode ser alterado na medida em que coloca em conflito a sua maneira usual de exposição. É nesse sentido que percebemos a importância de diferenciar os modos de exposição, pois eles constituem estratégias diversas, em que a imagem convida o enunciatário a um conjunto distinto de ações e contextos de interpretação. Em um museu, por exemplo, pode estar envolvido um forte 
convite à apreciação estética, configurando-se, assim, determinada prática interpretativa. Já a mesma imagem que aparece na capa de jornal pode cumprir outro papel, atestando a ocorrência de um fato e trazendo credibilidade à notícia. As estratégias que se apresentam contínuas ao longo da história são responsáveis pela formação dos estatutos (os tipos de imagem e as expectativas quanto ao modo de serem interpretadas), que podem ser subvertidos por determinados artistas quando constroem textos isolados. A arte contemporânea trabalha muito com o embaralhamento desses estatutos, trazendo fotografias das mais diversas origens ao contexto museológico (contestando não só o caráter artístico das imagens, mas o papel do museu).

O último nível de análise, aquele das formas de vida, diz respeito, segundo Fontanille (2011, p. 169), às “[...] deformações coerentes que afetam o conjunto dos níveis do percurso gerativo de um discurso ou de um universo semiótico qualquer, desde os esquemas sensoriais e perceptivos até as estruturas narrativas, modais e axiológicas." ${ }^{1}$ É dessa forma que é possível investigar o papel que a fotografia desempenha em determinada cultura.

Para este artigo, trataremos da obra de Claudia Andujar, fotógrafa suíça radicada no Brasil que dedicou sua carreira à temática indígena. Veremos, sobretudo, como a circulação de sua série fotográfica Marcados proporcionou diversos contextos de interpretação, ressignificando a relação entre trabalho documental e artístico do ponto de vista do estatuto dessas imagens e questionando o gênero da fotografia de identificação, que é constantemente tensionada com as características individualizantes do retrato fotográfico.

\section{A série Marcados}

$\mathrm{Na}$ história da fotografia brasileira, a causa indígena ganha visibilidade com o trabalho de Andujar. Desde o início de sua carreira, a fotógrafa conciliava a militância nessa causa com fotografias em preto e branco de cenas do cotidiano que já eram reconhecidas no circuito da arte2, assim como fotografias dos próprios Yanomami, realizadas em um contato

\footnotetext{
1 Tradução nossa. No original: "Une forme de vie est une déformation cohérente qui affecte l'ensemble des niveaux du parcours génératifs d'un discours ou d'un univers sémiotique quelconque, depuis des schèmes sensoriels et perceptifs jusqu'aux structures narratives, modales et axiologiques".

20 curador e crítico Pietro Maria Bardi (1958) comenta, em um texto de 1958, as origens do trabalho artístico de Andujar na pintura e elogia a adoção da fotografia em preto e branco no trabalho da artista, que mantinha
} 
inicial que se deu de 1971 a 1977. Na década de 1980, Andujar viaja acompanhada de dois médicos para uma expedição de salvação que percorre diversas tribos Yanomami da Amazônia com o objetivo de vacinar os índios que ali viviam contra uma epidemia que os atingiu em decorrência do contato com o homem branco na ocasião da construção de uma rodovia no local. Andujar tinha a tarefa de identificar os índios de diversas aldeias para produzir retratos que compuseram sua ficha médica. Uma vez que os Yanomami não respondem a nome próprio, para essa identificação foram feitas fotos de cada índio utilizando placas com uma numeração junto ao corpo (Figura 1), e essas fotos foram posteriormente incluídas nas fichas médicas de cada um deles.

Figura 1 - Exemplos de fotos de identificação dos índios e sua aplicação nas fichas médicas
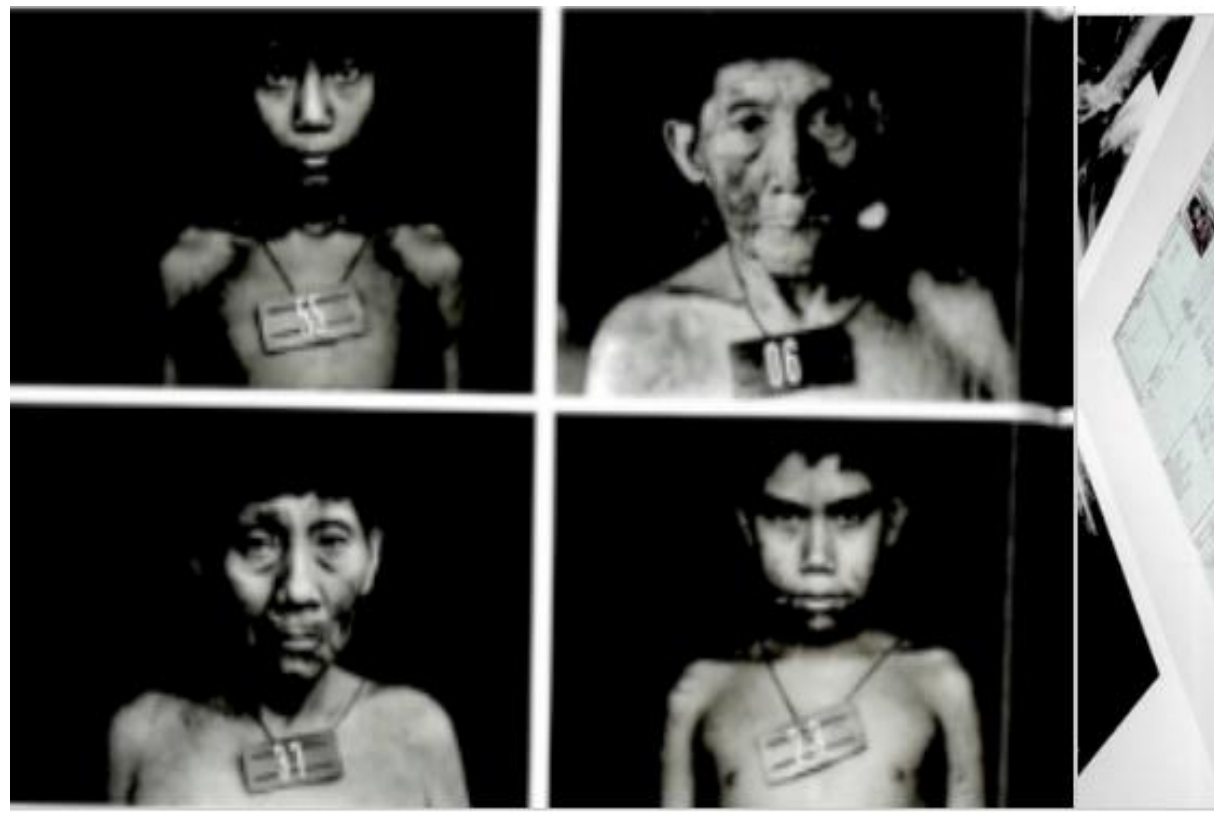

Fonte: Adaptado de Anjos (2014).

A série feita por Claudia, denominada Marcados, contém 82 imagens resultantes dessa expedição e circulou inicialmente ao lado de textos e relatórios produzidos pela fotógrafa durante a visita na região amazônica, publicados inicialmente em 1982 no relatório da Comissão pela Criação do Parque Yanomami (CCPY).

Em 2005, três dessas imagens são expostas pela primeira vez no circuito da arte, em uma galeria de Londres. A instalação levava o título de "Marcados para viver, marcados para

ainda, segundo Bardi, uma forte preocupação estética apesar dos temas cotidianos. 0 reconhecimento atual de Andujar no circuito da arte se expressa com a inauguração, em 2015, de um pavilhão expositivo dedicado à artista em Inhotim, maior museu brasileiro de arte contemporânea situado em Minas gerais. 
morrer", em uma alusão claramente intertextual entre a marcação que buscava preservar a vida dos indígenas e outros retratos nos quais as pessoas recebem um número e são identificadas antes de serem mortas. Nesse sentido, é importante notar que o Holocausto fez parte da vida da fotógrafa (que teve seu pai judeu levado para um campo de concentração e assassinado na época da Segunda Guerra Mundial), mas também se pode lembrar das recentes fotos de identificação recuperadas de um campo de concentração no Camboja ${ }^{3}$. É interessante ressaltar que, em um primeiro momento, aquele do uso dessas fotos como identificação nas fichas médicas, tal relação polêmica não encontrava espaço ainda para ser percebida, já que esse contexto inicial coaduna com aquele da história das fotografias de identificação, tanto no âmbito médico quanto policial, etc.

É só no contexto artístico que a polêmica e as relações intertextuais ganham terreno fértil, explorado pela própria autora, que passa a apontar - nas entrevistas que dá e nos textos que acompanharão as imagens - a ressonância do sentido de "marcados para morrer" no contexto do Holocausto e "marcados para viver" no contexto dos índios. Haverá, portanto, uma mudança do entendimento dessas imagens de acordo com sua inscrição em outra prática interpretativa, aquela das fotos de arte, na qual a ambiguidade de sentido é valorizada, assim como a exploração plástica do texto fotográfico.

Vale ressaltar o cuidado que devemos ter aqui ao compreender qual é o texto a ser analisado. Isso porque as imagens circulam em diferentes materialidades (impressas em um papel, na tela de um computador, nas paredes de uma exposição, etc.) e são consideradas, portanto, na situação semiótica em que se apresentam, no modo como emergem a partir de um horizonte de possibilidades. Assim, a primeira análise parte das imagens impressas no fotolivro, sendo esse o texto-enunciado analisado, cujo foco está tanto em seu encadeamento e apresentação das fotos dentro desse texto (nível da enunciação do texto-enunciado) quanto em sua relação com o gênero das fotografias de identificação e do retrato (relação entre o nível do texto-enunciado e dos estatutos das imagens). Avançando nos níveis de análise do plano da expressão, percebe-se que as imagens instauradas no suporte formal do livro fazem parte de uma situação semiótica na qual se instaura uma prática de leitura e fruição que estabelece determinados sentidos para o enunciatário que se depara com as imagens, os quais serão explorados adiante. Reconhecemos ainda que existe uma relação das imagens com outros elementos de design no fotolivro, como o tipo de papel, de

3 Ver De Duve, (2008) e Bracchi (2016). 
encadernação do livro, etc., configurando um nível do objeto que não adotamos como interesse central, pois tornaria a análise demasiado longa.

Em um segundo momento, as imagens no contexto da exposição configuram outro texto-enunciado. Temos aqui mais uma vez um nível objetal, em que se tornam significantes elementos como a iluminação recebida e a circulação no espaço expositivo como direcionamento de leitura. A configuração formal dessas imagens expostas participa de outras práticas de fruição, a partir das quais pensamos não só em uma leitura que se dá na espacialidade maior da sala expositiva (que faz outros convites ao corpo do enunciatário para entrar em contato com os retratos), mas na influência que o fato de estarem em um espaço museológico exerce sobre o espectador. Esse último fator coloca as imagens em uma referência direta com os estatutos, as cristalizações de práticas produtivas e interpretativas que caracterizam um gênero (seja ele documental ou artístico) e que a exposição dessas fotografias não cessa de questionar.

\section{A fotografia de identificação e o retrato a partir do fotolivro}

Após a primeira aparição artística como pequena exposição em 2005, um número maior de fotos é compilado em um fotolivro editado por Andujar e publicado em 2009 pela editora Cosac Naify. Marcados é uma publicação que reúne as 82 fotos divididas em sete tribos fotografadas de 1981 a 1984. Há ainda um texto de Stella Senra (2009), pesquisadora da área de cinema e fotografia, o relatório inicial de 1982, além de um texto de Andujar que abre a publicação. Nele, a artista ressalta o contexto do Holocausto em sua história pessoal. Revela-se para o leitor a ambiguidade do sentido de marca e a crítica ao método de rotular pessoas com números de identificação. A capa da publicação (Figura 2) reproduz parte da primeira imagem mostrada no livro, ocultada por uma tarja preta que reforça visualmente a presença da marca, exaltando a plasticidade da cor negra presente na placa numérica sobre o corpo dos índios, ainda que a todo o momento a presença do negro e sua oposição (o branco) faça parte da publicação composta inteiramente por fotografias em preto e branco. 
Figura 2 - Capa do livro Marcados

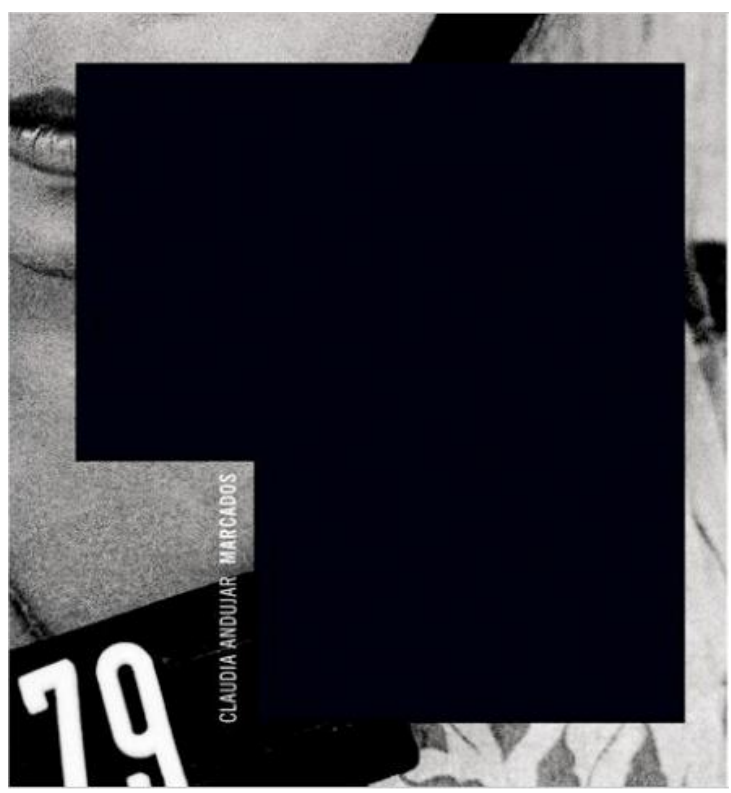

Fonte: Andujar (2009).

As primeiras fotografias do livro são de crianças, reforçando a ideia de início temporal da série. Já aqui, o cara a cara estabelece-se com o leitor, assim como um jogo de identificação de sensações, como medo, desconfiança e curiosidade no semblante dos pequenos indígenas. Nesse ponto, vale refletir sobre o costume ocidental de concentrar no rosto a expressão de si e das emoções. Por um lado, sabemos da importância do rosto até pelo papel que ele tem nos enunciados de uma língua oral, conforme aponta Deleuze e Guattari (1996, p. 43):

Uma língua está sempre presa a rostos que anunciam os enunciados dela, que os lastream em relação aos significantes em curso e aos sujeitos concernidos. É pelos rostos que as escolhas se guiam e que os elementos se organizam: a gramática nunca é separável de uma educação dos rostos. 0 rosto é um verdadeiro porta-voz.

No entanto, no caso dos indígenas e dos povos não ocidentais, não podemos afirmar tão facilmente que o rosto funcione como o principal mecanismo de demonstração e reconhecimento de emoções e estados de alma, pois tais expressões passam por um aprendizado sobre o corpo que lança as bases culturais para a manifestação da subjetividade. 0 ocidente cria uma espécie de máquina que atribui e reconhece sentido no 
rosto, sendo o rosto sofrente de Cristo o ápice de tal expressão. Por isso, Deleuze nos convida a indagar o sistema de expressão de outros povos:

Se considerarmos as sociedades primitivas, poucas coisas passam pelo rosto: sua semiótica é não-significante, não-subjetiva, essencialmente coletiva, polívoca e corporal, apresentando formas e substâncias de expressão bastante diversas. A polivocidade passa pelos corpos, seus volumes, suas cavidades internas, suas conexões e coordenadas exteriores variáveis (territorialidades). (DELEUZE; GUATTARI, 1996, p. 38-39).

Essa discussão sobre o modo de olhar ocidental para aspectos que podem não ser valorizados em outras culturas evoca ainda uma outra discussão sobre como tornar socialmente visível outros povos, com outros valores e outros modos de construção de sua identidade4. É por isso que vale a pena ressaltar que, ainda que profundamente engajada na causa indígena, os retratos são a visão de Andujar sobre os Yanomami, resguardando um ponto de vista próprio a esse enunciador e sua cultura. É interessante notar, no entanto, que Andujar busca compreender a representação indígena sobre temas emergentes. Nesse sentido, ela disponibilizou, em suas viagens, papel e caneta para que os índios desenhassem as histórias que contavam. Esses desenhos são expostos juntamente com os retratos na mostra de 20145, evidenciando uma forma de representação gráfica dos indígenas muito distante da perspectiva linear presente tanto na fotografia quanto nas gravuras que aparecerem na sala expositiva. Ainda hoje, quando expostos isoladamente em uma das salas do pavilhão dedicado à artista no museu de Inhotim, esses desenhos interrogam o modo como devem ser lidos, qual o código atuante nessas representações, e recoloca o público de uma galeria de arte no lugar de alteridade em relação às histórias e ao modo de narrar e sentir dos índios.

Após o conjunto inicial de crianças, vão surgindo, no fotolivro, as figuras de adultos, especialmente mulheres que entendemos ser as mães dessas crianças (a partir da pose em que as seguram). Ao final das fotos da primeira tribo, o primeiro homem aparece. Há, então, uma pausa visual em uma página inteiramente em preto. Esse ponto de parada mostra que um início de narrativa aconteceu e abre espaço para mostrar, então, a diversidade das tribos

\footnotetext{
4 Ressaltamos aqui a iniciativa do Vídeo nas Aldeias ([201-]), que desde 1997 capacita os próprios indígenas para a produção de conteúdo audiovisual sobre os temas que eles elegem como importantes.

5 A exposição de 2014 da série ocorreu em São Paulo, no Instituto Tomie Ohtake, e a de 2013, na Galeria Vicente do Rego, em Recife. Analisaremos, mais adiante, cada uma das exibições.
} 
Yanomami. Tal início é uma espécie de cosmogonia de surgimento do mundo no espaço da publicação, com o homem aparecendo por último, após crianças e mulheres.

A estratégia linear de apresentação dos retratados, partindo das crianças até o homem adulto, existe apenas no livro, pois a exposição de 2013 traz os retratos agrupados em polípticos e, naquela de 2014, as imagens das crianças estão entremeadas com a dos adultos. Enquanto isso, o espaço mais dilatado do livro permite a ocorrência de pequenas séries que podem ser notadas por meio de similaridades, como o conjunto de quatro imagens, em sequência, de mulheres com a mesma estampa de vestido, o que nos faz interrogar se seria de fato a mesma vestimenta (Figura 3).

Figura 3 - Sequência de retratos de mulheres usando vestido de mesma estampa

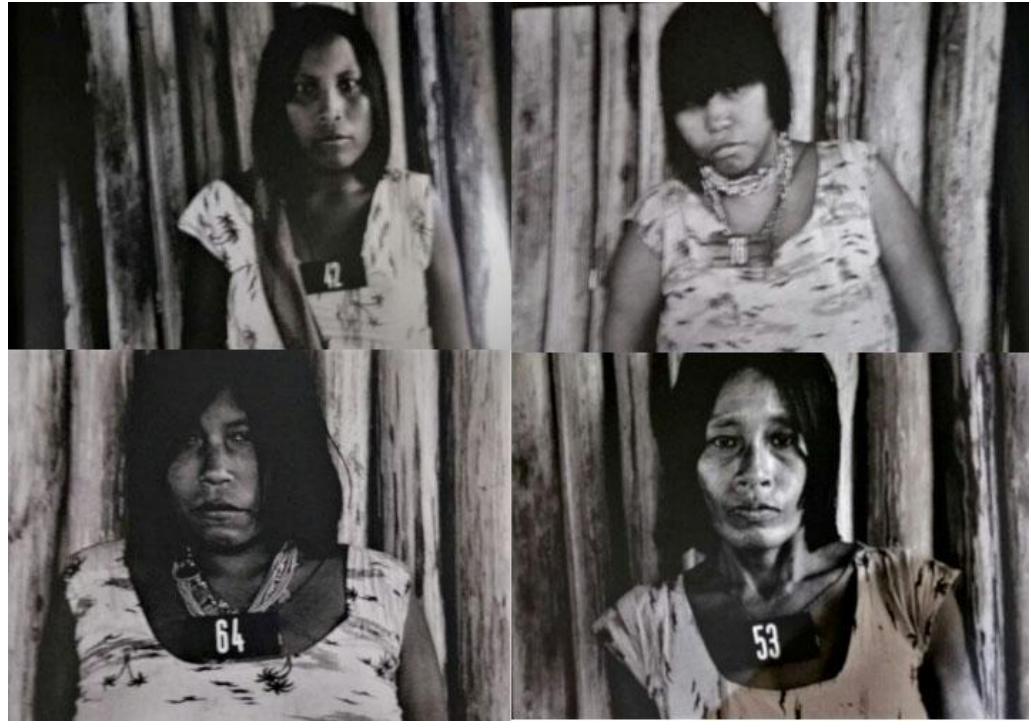

Fonte: Andujar (2009).

Esse tipo de série reforça o tema da padronização já evocado na tipificação composicional dos retratos de identificação. A reiteração vestimentar ocorre ainda outras vezes ao longo do livro, em um jogo de semelhanças não só de estampas, mas de um povo. No entanto, tais semelhanças tornam mais nítidas também as singularidades de olhares e posturas gestuais. 0 social, o comunitário e o tribal ambiguamente também revelam o individual.

Há um tipo de cenário neutro para cada tribo, que varia entre muros de madeira, mata e até mesmo um fundo preto em que o modelado do claro e escuro é mais intenso. Nesse ponto, é interessante lembrar que todas as fotos no interior do livro estão sobre um fundo preto, o que ganha um efeito mais forte de luz e sombra quando os retratos da tribo 
Aracá, cujos índios também foram colocados sobre um fundo preto, tem suas figuras flutuando no espaço escuro, conforme observamos na Figura 4.

Figura 4 - A tribo Aracá na série Marcados (1981-1983)
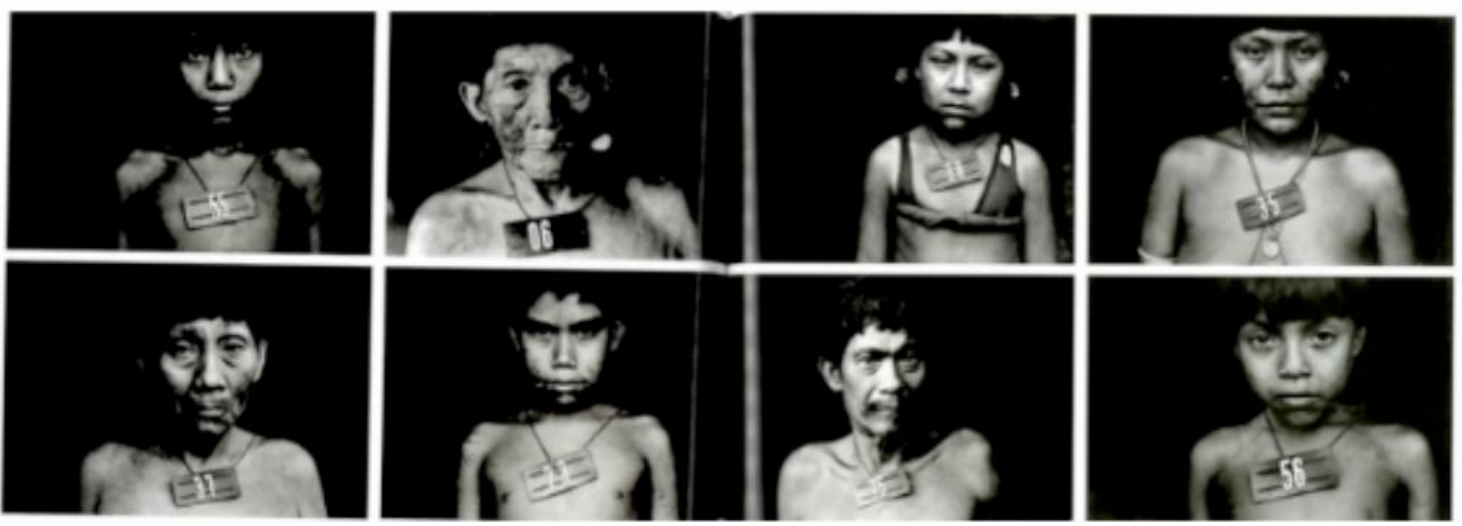

Fonte: Adaptado de Andujar (2009).

Vale a pena lembrar, no entanto, que essas fotos foram concebidas como forma de identificação da população indígena em situação de vulnerabilidade, ainda que apresentem forte contraste entre preto e branco, o que dramatiza o ator do enunciado, o índio. Do ponto de vista do texto-enunciado, os demais elementos de expressão da fotografia levam-nos a interpretá-la, no nível dos estatutos, como uma foto de identificação: os padrões objetivos de captura, o enquadramento rígido, o achatamento das formas, a emersão da figura que vem de um fundo neutro, a frontalidade e o destaque do rosto e do busto. Esses elementos são base para observarmos, no plano do conteúdo, a rigidez dos corpos dos índios, que não estão à vontade diante da câmera, desse outro que os fotografa. Além disso, há a ligação marcante estabelecida por uma justaposição espacial do rosto com a placa de numeração, que precisa estar bem focalizada, o que marca fortemente uma oposição entre identidade (que é valorizada na busca pela singularidade da fisionomia) e alteridade (que se dá na diferenciação de um índio para o outro no suceder de fotos do livro). A identidade é gestada pela iniciativa do homem branco de identificação e aparece como imposição na medida em que tal identificação aparece exprimindo também uma postura rígida dos corpos e do enquadramento escolhido.

Chama a atenção, desde o início do livro, o jogo de olhares que se estabelece: sua complexificação afasta tais retratos do típico olhar para a câmera (direto, mas ausente), característico dos retratos de identificação. Na segunda tribo apresentada, por exemplo, vemos um jogo de olhares mais complexo: um bebê que chora com os olhos fechados, 
crianças que olham para fora do campo visual da fotografia, mais olhos fechados e uma intrigante imagem (Figura 5), na qual os olhos do retratado estão imersos na escuridão, o que nos apresenta uma outra forma de ausência do olhar. A existência radical do olhar que desaparece no escuro é algo notado apenas no livro, que se dá na medida em que o leitor passeia pela sucessão linear dos olhares e está ausente na exposição das fotos em museus.

Figura 5 - Retrato de índio da tribo Aracá

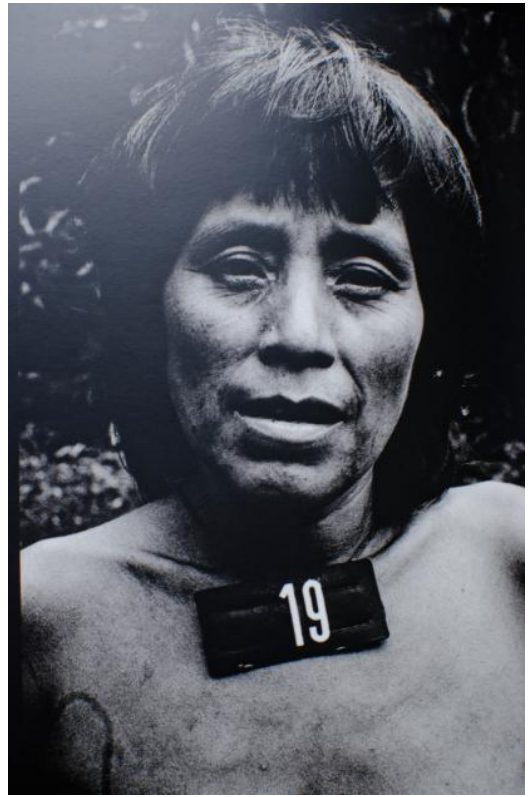

Fonte: Andujar (2009).

Desse modo, percebemos a existência de um espectro de maior ou menor interação entre enunciatário e o índio ator do enunciado de acordo com os jogos de olhares que se dão nessas imagens. Representamos graficamente essas posições na figura a seguir.

Figura 6 - Maior e menor grau de interação visual no jogo de olhares entre ator do enunciado e enunciatário
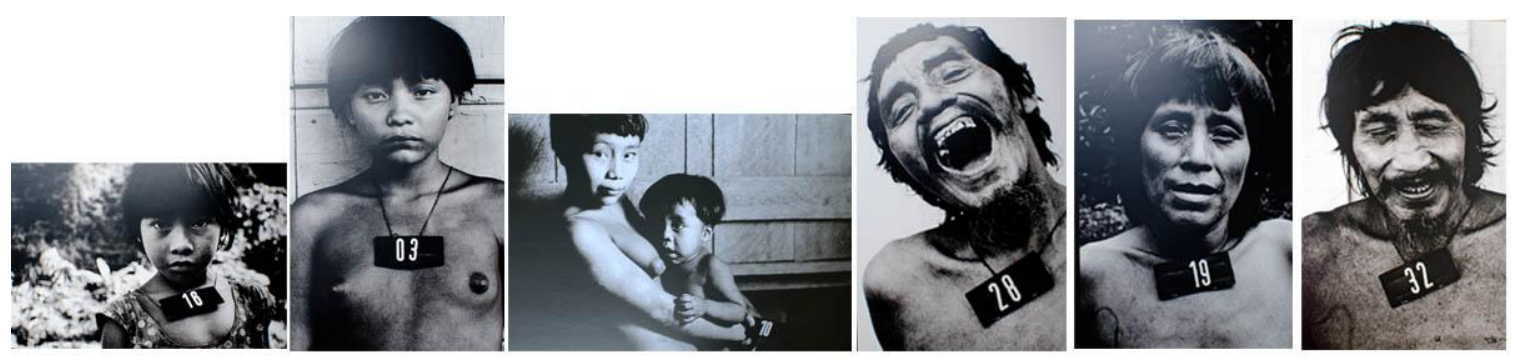

Maior contato visual

Menor contato visual

Fonte: Adaptado de Andujar (2009). 
Em um maior grau de interação, está o olhar de frente, que, associado a expressões faciais, nos faz reconhecer aí uma interação e o desvelar de emoções no rosto do fotografado (ainda que tal jogo de identificações seja uma prática ocidental, conforme já apontamos). Em segundo lugar, temos os índios que nos olham diretamente, mas com uma expressão facial vazia. Em seguida, o olhar lateral, de soslaio, que retira o corpo do enunciatário da frontalidade da interação e o coloca como percebedor de uma cena em desenvolvimento, da qual se vê flagrado observando. Em quarto lugar, apontamos o marco de um olhar desfigurado pela careta e o jogo de olhares interrompido pelo fechamento parcial dos olhos. Por último, temos a posição radical do olhar obscurecido pela escuridão, que interrompe a interação visual com o enunciatário, assim como os índios que aparecem de olhos fechados.

Conforme o trabalho de identificação vai avançando, os índios parecem estar mais confortáveis diante da câmera, e Andujar, por sua vez, parece aproveitar-se dessa intimidade iminente, produzindo imagens muito mais próximas de verdadeiros retratos em oposição às fotos de identificação. Nas fotos mais recentes do projeto (Figura 7), o enquadramento é mais flexível, com uma abertura maior do campo visual, para que sejam capturadas características corporais e fisionômicas peculiares dos índios, além de uma renúncia maior da frontalidade e do fundo neutro, passando a ser aproveitado o fundo natural do ambiente onde os retratos foram feitos.

Figura 7 - Fotos da série Marcados que tendem mais ao retrato do que à foto de identificação

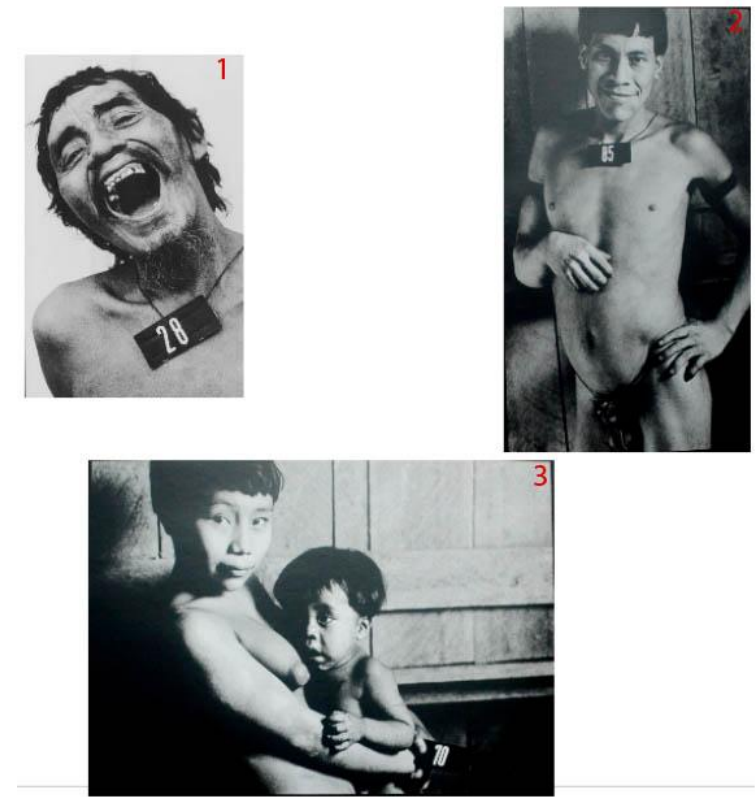

Fonte: Adaptado de Andujar (2009). 
Nessas três últimas imagens, vemos que as características das fotos de identificação são, de certa forma, abandonadas. Assim, no plano do conteúdo, a oposição entre identidade e alteridade é desfeita ou ao menos diluída; além disso, a identificação dos índios não é feita mais pelo rosto ou pela placa numérica, mas por gestos, sorrisos e poses que os individualizam (uma característica do retrato fotográfico). Além disso, em oposição à rigidez dos corpos na foto de identificação, há, no retrato, um relaxamento desses corpos: de tão confortáveis, eles desafiam aquele que os olha (fotografia 2 da Figura7), ou seja, o fotografado passa a interpelar ativamente o enunciatário.

Percebe-se aqui uma construção significante do corpo por meio da diferença entre a rigidez inicial dos primeiros retratos do livro e o relaxamento dessas três últimas imagens. Assim, de acordo com uma semiótica do corpo proposta por Fontanille (2004), percebemos nas imagens que a rigidez está associada a uma domesticação do corpo própria da esfera da cultura. Isso se dá na medida em que está mais associada aos parâmetros culturais da fotografia de identificação enquanto uma prática produtiva que obedece às normas, exercendo uma programação no corpo do actante e regulando sua pose. Enquanto isso, o relaxamento está presente nas últimas imagens, de modo a mostrar outros temas relacionados aos índios (especialmente o tema do cuidado, presente no retrato da mãe com o filho), proporcionando uma abertura do entendimento do que há de mais característico nesses indivíduos - como um convite ao espectador para que perceba outros temas importantes para a essência dos indígenas - e situando essas fotos como mais próximas do valor fundamental da natureza. A falta de programação e a abertura das possibilidades de sentido localizam essas últimas imagens em uma relação de ajustamento do fotógrafo com o fotografado, na qual há uma abertura para o olhar mais relaxado e interativo, como vemos no retrato do índio 2 da figura 7, ou ainda a criação do efeito de sentido de surpresa quando nos deparamos com o largo riso do indivíduo 1 da figura 7.

Esse relaxamento também é figurativizado no riso, que impede a identificação das características fisionômicas do índio (fotografia 2 da Figura 7), negando a grande função das fotografias de identificação ${ }^{6} .0$ que passa a valer nos retratos ao longo do livro não é mais a identificação de uma aparência, mas de uma essência, das qualidades emocionais de cada

\footnotetext{
6 Lembramos aqui a estratégia de alguns presos de fazerem caretas e procurarem deformar o rosto justamente para não serem identificados quando eram submetidos às fotos policiais. 0 riso largo é, portanto, visto como um dificultador da identificação e negado na fotografia de identificação, de modo que até hoje não podemos fazer isso nas nossas fotos de passaporte, etc.
} 
membro da aldeia, em oposição às fotos de enquadramento seriado, apresentadas no início do livro. Já na terceira foto da Figura 7, as características do retrato são totalmente ressaltadas. Nela, há a diagonalidade da pose da índia segurando uma criança, e a placa de identificação é deixada como elemento periférico no enquadramento, em uma composição que abre espaço para se pensar o tema da maternidade, do acolhimento e do cuidado. Essa composição deixa ver diferentes temáticas e investe em valores eufóricos: a imagem do índio e a relação da fotógrafa com o povo indígena, em oposição ao que acontece no conjunto de imagens do início do livro.

Percebemos, então, que a questão semiótica fundamental presente no fotolivro Marcados é a mudança de gênero que essas fotos perfazem ao longo do livro. De maneira linear, as primeiras imagens iniciam o livro atendendo a todos os atributos de uma foto de identificação, elas estão de acordo com a prática produtiva dessas imagens e seu enquadramento característico. No entanto, ao longo do livro vamos percebendo outros modos composicionais e jogos de olhares, abrindo caminho para o entendimento dessas imagens como retratos que marcam não só aquilo que é mais típico das feições indígenas, mas outros temas importantes como o cuidado materno, a busca pela preservação dessas vidas, etc. Dessa maneira, podemos afirmar que as práticas produtivas desses retratos e o modo de fotografar vão se alterando junto com a nossa prática interpretativa dessas imagens. Vamos percebendo as outras nuances e os outros temas subjacentes, até o ponto de subverter o entendimento do livro como um agrupamento de fotografias de identificação e ver o tema da euforização da vida dos índios, cuja marca negra é o primeiro e mais concreto passo no percurso de preservação da vida.

Interessa-nos, a partir de agora, verificar como esses sentidos circulam e proporcionam, a partir da mesma série exposta no museu, diferentes possibilidades de interpretações que consolidam diferentes estatutos para as imagens.

\section{Galeria Vicente de Rego Monteiro}

De 16 de maio a 27 de julho de 2013, a série Marcados foi exibida na Galeria Vicente do Rego Monteiro, em Recife, como parte da programação do projeto Política da Arte, sob curadoria de Moacir dos Anjos. Na montagem (Figura 8), foram expostas 65 fotos da série distribuídas em diversos polípticos, cada um mostrando índios da mesma aldeia. Na sala de 
exposição, havia uma mesa em que eram exibidos relatórios médicos sobre a tribo Yanomami, a reprodução das fichas médicas dos índios com as mesmas fotos feitas por Claudia em tamanho pequeno, mapas com a localização das aldeias e fotos dos tratamentos médicos realizados durante a expedição na Amazônia.

Figura 8 - Sala de exposição e detalhe com a reprodução das fichas médicas e documentação fotográfica dos tratamentos médicos

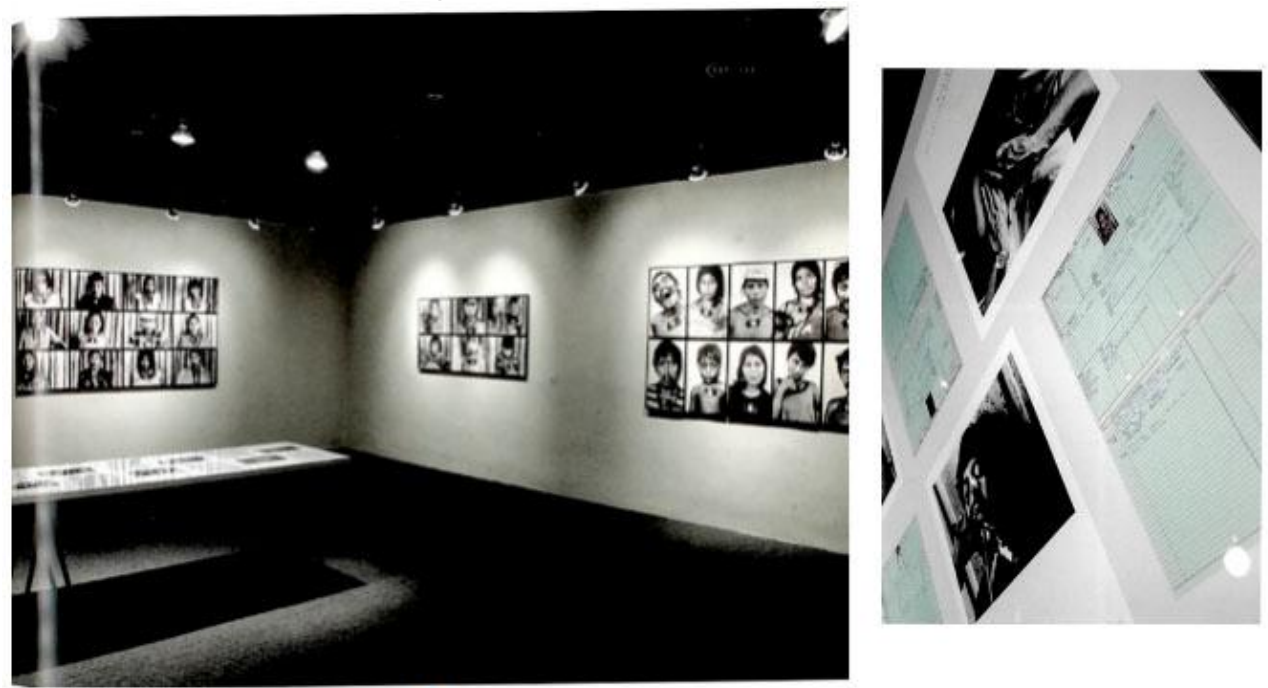

Fonte: Adaptado de Anjos (2014).

Considerando a expografia como um texto, temos, do ponto de vista do plano da expressão, uma luz concentrada que dramatiza a cena e direciona a leitura, estabelecendo uma relação direta entre as fotografias expostas nos polípticos e a mesa, que contém as fichas médicas, com as mesmas fotos em tamanho menor (tipo 3x4) anexadas aos documentos - uma espécie de prontuário.

Em relação ao plano do conteúdo, nos polípticos são utilizadas muitas das fotos não típicas da foto de identificação, acentuando, de maneira eufórica, a relação entre identificação e preservação da vida. Da forma como a exposição é montada, os índios estão, então, marcados para viver, isto é, há uma valorização eufórica do contato com o branco, que também pode ser percebida na escolha dessas fotos menos típicas, porque mostram conforto e intimidade na relação branco-índio que se deu na interação entre fotógrafo e fotografado. Os índios passam de identificados a retratados. Temos, portanto, nessa montagem, uma narrativa de conjunção com a vida e de euforização do contato, figurativizada, no nível discursivo, pelos elementos de isotopia da preservação - como as 
fichas, os retratos dos tratamentos médicos, os mapas da aldeia, os relatórios - e de relaxamento - como o riso, a pose, o olhar ativo.

Além disso, esses elementos de preservação ancoram-se em um tempo (as fichas estão datadas) e um espaço (o mapa com a localização das aldeias indígenas), e, dessa forma, situam o enunciatário em um contexto que retoma as condições de produção dessas imagens e faz com que as fotos ganhem um estatuto mais político de um acontecimento social. 0 poder estético das imagens nos polípticos é, então, o de rememorar um acontecimento.

Podemos afirmar, por um lado, que a estratégia plástico-discursiva da exposição direciona o enunciatário para a compreensão dessas imagens como imagens características do gênero da foto de identificação, quando privilegiam sua valorização prática documental, de exposição das características fisionômicas, uma vez que essas fotos estão presentes em seu contexto original como retratos de tamanho $3 \times 4$ fixados nas fichas médicas. No entanto, há também uma valorização artística dessas imagens enquanto retratos expostos na parede e iluminados por uma luz de ponto focal. É a partir desse último modo de interação que o corpo do enunciatário é convocado em maior grau, na medida em que essas imagens se impõem tanto por seu maior tamanho quanto pela valorização plástica dos jogos de luz e sombra dos retratos em preto e branco. 0 engajamento sensorial aqui é maior, de modo que o sensível é convocado pelo cara a cara dramático que se estabelece entre o espectador e o retrato iluminado dos índios na parede da galeria. Já o inteligível manifesta-se em maior grau na mesa que exibe as fichas médicas e a documentação dos tratamentos recebidos pelos índios. Ambos, sensível e inteligível, atuam para uma narrativa eufórica de preservação da vida.

\section{Instituto Tomie Ohtake}

No Instituto Tomie Ohtake, em São Paulo, a exibição das fotografias da série Marcados ocorreu entre 18 de agosto a 5 de outubro de 2014, como parte da exposição Histórias Mestiças, sob curadoria de Adriano Pedrosa e Lilia Moritz Schwarcz. A mostra tinha como objetivo reunir mais de 400 obras de artistas brasileiros e estrangeiros que contribuíram, em diversas épocas, para a construção de narrativas que formam a identidade brasileira. 
A sala em que estava a obra de Andujar (Figura 9) era composta por 47 fotos da série Marcados, que dialogavam com 38 aquarelas produzidas entre 1771 e 1773 por Joaquim José de Miranda e que figurativizavam a história da catequização e a posterior resistência dos índios, que são colocados como vilões. Além disso, havia um conjunto de desenhos feitos por Taniki Manippi-theri, um dos índios Yanomami, a partir de materiais levados por Claudia para a aldeia e que, por sua vez, contavam a história da morte de uma mulher Yanomami. É importante notar que não havia nenhum texto explicativo na sala de exibição e essa foi a primeira vez em que os elementos contextuais desse trabalho de Andujar foram suprimidos. Não se podia ver, por exemplo, o território Yanomami demarcado ou o contexto em que essas fotos circularam inicialmente (as fichas médicas). Até então, tal descontextualização seria impensável, conforme podemos perceber no catálogo da exposição anterior, de 2013, em que o curador afirma que sempre era dado ao público saber o que motivou essas fotografias enquanto contexto importante da obra (ANJOS, 2014).

Figura 9 - Exposição da série Marcados em 2014, no Instituto Tomie Ohtake

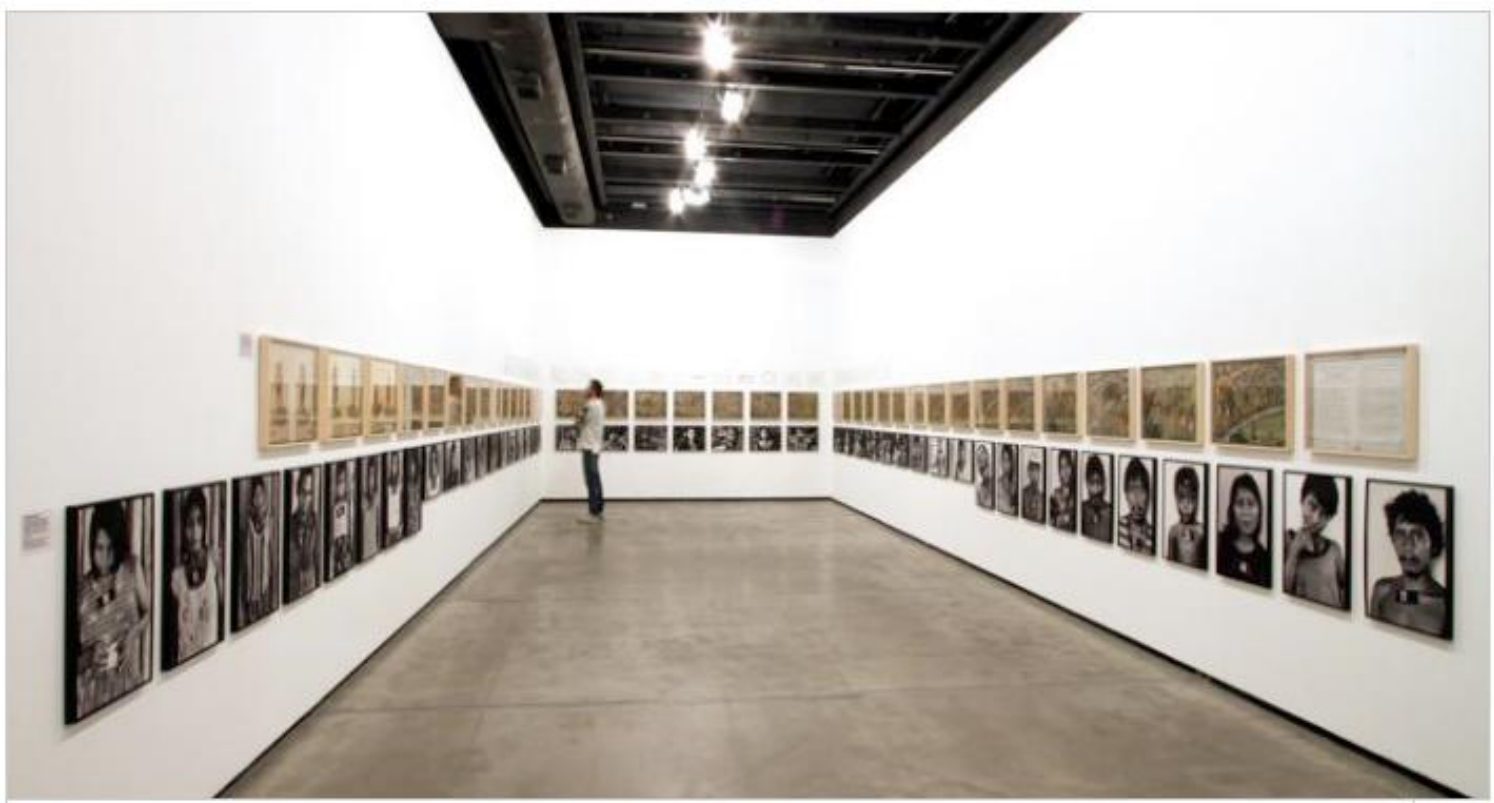

Fonte: Adaptado de Pedrosa; Schwarcz (2014). 
Figura 10 - Detalhe da exposição da série Marcados em 2014
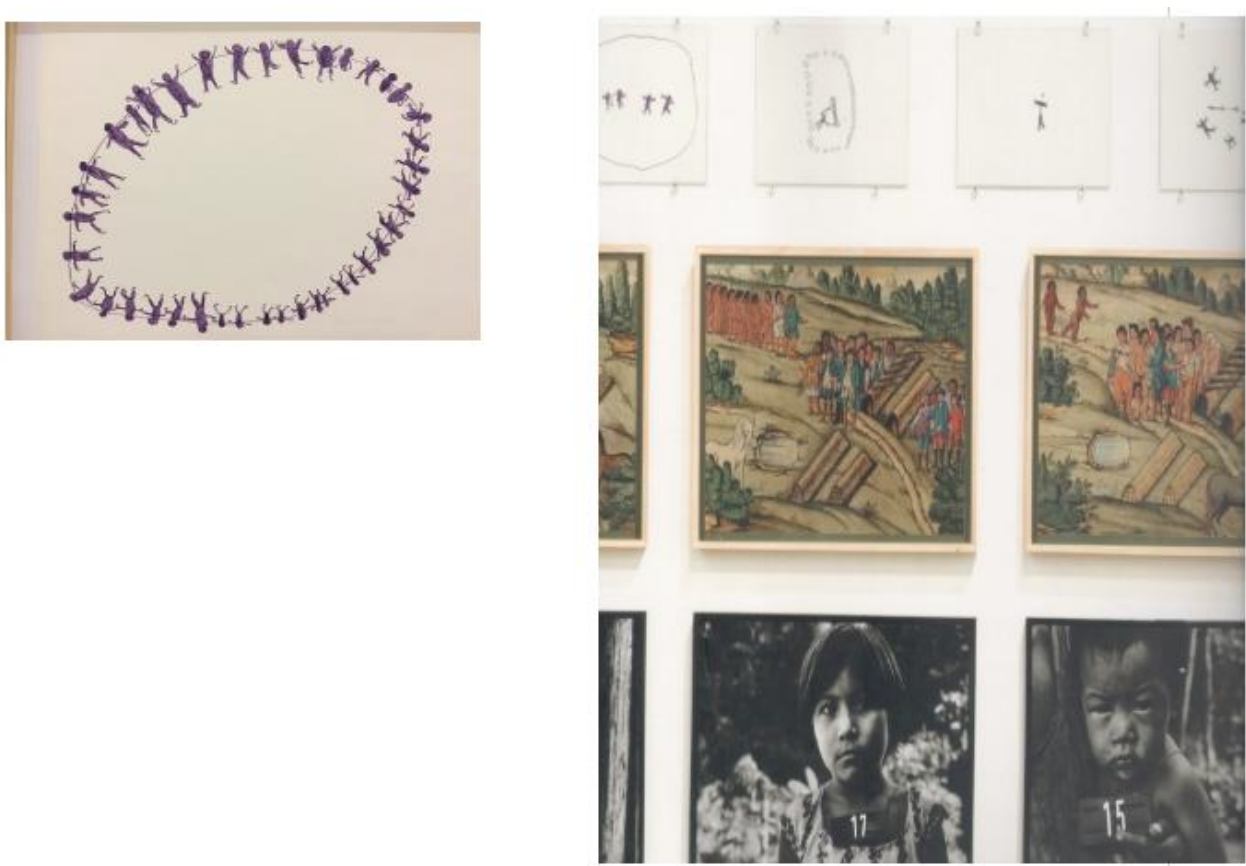

Fonte: Adaptado de Pedrosa; Schwarcz (2014).

Nota: na esquerda, detalhe de desenho feito por Taniki Manippi-theri. Direita: detalhe da salade exposição com as fotos da série Marcados

Do ponto de vista do plano da expressão, a luz difusa, que não privilegia um percurso ou um elemento, ao contrário do que ocorre na exposição em Recife, não direciona o olhar do espectador a uma leitura específica, deixando-o livre para fluir linearmente ou verticalmente nos conjuntos montados de maneira sobreposta. A instituição adota as diretrizes mais típicas da busca por um museu da pretensa isenção e neutralidade na exposição de obras, conforme descrito por Brian O’Doherty (1999) como modelo do "cubo branco"7. As regras arquitetônicas para tal efeito de sentido de neutralidade podem ser rígidas. Não só a pintura branca das paredes, mas janelas lacradas e o teto como única fonte de luz, chão de madeira polido ou mesmo acarpetado para que se possa fruir as obras sem interferência externa (O'DOHERTY, 1999, p. 4).

Enquanto isso, a relação - forçada pela disposição da montagem - das fotos com as narrativas de catequização dos índios (aquarelas) e da morte de uma mulher Yanomami (desenhos), ambos figurativizando o tema da morte, ressalta a ideia de que os índios

\footnotetext{
7 autor define tal sistema de visibilidade da arte, apelidado de "Cubo Branco", como “[...] um pouco da santidade da igreja, da formalidade do tribunal, da mística do laboratório de experimentos que se junta a um projeto chique para produzir uma câmara estética única." (O’DOHERTY, 1999, p. 4).
} 
retratados e identificados nas fotos de Andujar se engajam numa narrativa de disjunção com a vida, isto é, foram "marcados para morrer". Há, portanto, uma valorização disfórica do contato.

Além disso, a falta de legendas ou informações na sala de exposição que contextualizem as fotos dificulta a leitura das narrativas, que somente podem ser recuperadas pelas explicações no catálogo. Junto a isso, não há uma marca precisa de um tempo ou um espaço, o que leva o espectador a contemplar e fruir esteticamente as imagens em um tempo presente, que é o do percurso na sala de exposição.

Assim, percebemos que, nessa última exposição, a prática museal de valorização estética das imagens - conforme uma estratégia já consolidada de apresentação do objeto artístico - e a desvalorização do contexto documental de onde partiram termina por sedimentar essas imagens em um estatuto artístico. Há, no entanto, a perda importante da construção do tema do cuidado e da preservação da vida. É importante observar que, ainda que essas fotos estejam colocadas como uma imagem atual dos índios, em contraposição com sua representação nas aquarelas do século XVIII, o espaço expositivo e sua configuração asséptica pouco favorece um envolvimento corporal do enunciatário com as imagens. Enquanto isso, há uma tensão entre os sentidos estabelecidos em discursos tão distintos (retratos, aquarelas e desenhos) sem que emerja daí uma compreensão final, ainda mais vazia pela falta de elementos que ancorem a significação das imagens.

\section{Considerações finais}

Os três contextos de circulação da série Marcados (o fotolivro e as duas exposições) revelam a importância de se considerar os níveis de pertinência da análise do texto visual. No contexto de exposição das fotos no livro pudemos observar que há uma enunciação encadeada pelo desenrolar das páginas e que subverte o tipo de imagem aí encontrado, indo desde fotos de identificação até retratos. Fica evidenciado, portanto, uma mudança de práticas produtivas de composição do retratado que se converte em uma mudança nas práticas interpretativas que utilizamos para compreender tais retratos e seu subtemas.

Já as exposições museais dessas imagens possibilitaram a observação mais a fundo do trânsito dessas fotografias entre um estatuto documental e o artístico. Em proporções sempre cambiantes entre esses dois polos, os retratos apareceram ora ligados às fichas 
médicas em que foram inicialmente utilizados e ora valorizados pela plasticidade e presença cativante da figura dos indígenas. Foi na consideração de cada exposição que se pôde observar com mais clareza a construção de um sentido eufórico ou disfórico para o contato dos brancos com os índios, e de uma maior ou menor possibilidade de entendimento da causa indígena a partir da presença de elementos que vão além das imagens da série Marcados. Os retratos dos índios Yanomami, quando expostos em Recife, ganham estatuto político, documental e rememoram um acontecimento. Posteriormente, em São Paulo, são valorizados de maneira contemplativa dentro de uma prática museológica canônica de exposição artística.

As diferentes maneiras de se conceber uma imagem e fazê-la circular produzirão sentidos diferentes a depender da situação semiótica em questão. Diferentes práticas estimulam a subversão de estratégias já consolidadas, levando a mudanças no estatuto das imagens ou o realce de um determinado estatuto em maior ou menor grau. Do mesmo modo, diferentes estratégias convidam o enunciatário a modos diversos de experiência e interação com a obra, podendo convocar mais o seu campo inteligível ou o sensível, ou ainda subverter estratégias inteligíveis ou sensíveis antes associadas a um procedimento já consolidado.

Pudemos observar que o engajamento sensorial na exposição do Recife, proporcionado pela iluminação concentrada e pelo tamanho das fotos dispostas espacialmente em polípticos, era mais exacerbado do que na exposição em São Paulo, onde a galeria asséptica, a luz difusa e uniforme e a possibilidade de percurso proporcionada pela expografia tendiam a convocar o enunciatário ao inteligível. Já a temporalidade do fotolivro, que desfaz o gênero foto de identificação, permite que o inteligível dê lugar ao sensível, sobretudo na relação do olhar do fotografado com quem o olha.

O caso desses três modos de expor a série de imagens deixa claro a importância de se analisar níveis maiores que o do próprio texto-enunciado para se compreender os sentidos que nascem junto com cada modo de exibição e circulação das fotografias, sobretudo contemporaneamente, quando os fotógrafos documentaristas estão buscando novos modos de enunciar, incorporando, em suas produções, procedimentos antes privilegiados no campo artístico. 


\section{Referências}

ANDUJAR, Claudia. Marcados. São Paulo: Cosac Naify, 2009.

ANJOS, Moacir. Política da Arte. Recife: Fundação Joaquim Nabuco, 2014.

BARDI, Pietro Mari. From a line to a smile. Revista Habitat, São Paulo, n. 48, 1958.

BRACCHI, Daniela. Exposição e significação: uma análise sobre os retratos de prisioneiros do Camboja. Revista Significação, São Paulo, v. 43, n. 45, 2016.

DE DUVE, Thierry. A arte diante do mal radical. Ars, São Paulo, v. 7, n. 13, jan./jun. 2008.

DELEUZE, Gilles; GUATTARI, Féliz. Mil platôs: capitalismo e esquizofrenia. Rio de Janeiro: Ed. $34,1996.3$ v.

DONDERO, Maria Giulia; BASSO FOSSALI, Pierluigi. Sémiotique de la photographie. Limoges: PULIM, 2011.

FONTANILLE, Jacques. A semiótica do corpo: entre psicanálise, fenomenologia e antropologia. In: CORTINA Arnaldo; MARCHEZAN, Renata (org.). Razões e sensibilidades: a semiótica em foco. São Paulo: UNESP, 2004. p. 89-116.

FONTANILLE, Jacques. Pratiques sémiotiques. Paris: PUF, 2008.

FONTANILLE, Jacques. Corps et sens. Paris: PUF, 2011.

O’DOHERTY, Brian. No interior do cubo branco: a ideologia do espaço na arte. São Paulo: Martins Fontes, 1999.

PEDROSA, Adriano; SCHWARCZ, Lilia. Histórias Mestiças: catálogo. Rio de Janeiro: Cobogó, 2014.

SENRA, Stella. O último círculo. In: ANDUJAR, Claudia. Marcados. São Paulo: Cosac Naify, 2009. p. 127. 
VÍDEO NAS ALDEIAS. Olinda, [201-]. Disponível em: http://www.videonasaldeias.org.br. Acesso em: 17 mar. 2019. Organização não governamental brasileira de na área de produção audiovisual indígena.

\title{
The project Marcados, by Claudia Andujar: a discussion of photographic practices and genres.
}

\begin{abstract}
This work is based on the plastic analysis of indigenous portraits by the photographer Claudia Andujar to explore the meaning of these images in their journey through time in different media and contexts of exhibitions. The purpose of this work is to analyze the variety of ways in which these portraits circulate and establish themselves as belonging to different interpretive practices. For this investigation, the methodology used is the analysis of the levels of signification proposed by Fontanille in his research on semiotic practices and, more directly, the unfolding that was done by Dondero \& Basso Fossali in proposing a Semiotics of Photography. The analysis reaches mainly the conclusion about important changes in the way of interpretation of these images in the photobook and in the exhibitions once the tension between the apprehension of these photos as a document and its inscription in the artistic scope is constantly present.
\end{abstract}

\section{Keywords}

Photography. Portrait. Claudia Andujar. 